\title{
Investigation on the Revolution and Need of Energy Efficient Smartphone Development
}

\author{
S.Pandikumar \\ Dept of Computer Science, \\ Subbalakshmi Lakshmipathy College of Sciene, \\ Madurai, India.
}

\begin{abstract}
Nowadays Smartphones act as a PA (personal assistant) to most of the people and it offers essential services such as Mobile Internet, Geo Location and Maps, Multimedia Services, High Data Rate Connectivity and much more. Especially present younger generations accept Smartphones as a part of their life. Smartphone Apps (applications) are the heart of all phones and these Apps drain the Smartphone's battery dramatically. The full degree of freedom in mobile systems heavily depends on the energy provided by their batteries. In general, their capacities are limited and for sure, not keeping pace as the mobile devices are crammed up with new functionalities. Moreover, battery capacity is significantly restricted due to constraints on size and weight of the device. This paper discusses the importance of energy efficient Smartphone developments. The mobile batteries are analyzed and the clear picture of their deficiency and the revolution of capacity from Lead acid to Li-Ion are given. This paper also states the importance of energy efficient Apps developments from various perspectives.
\end{abstract}

\section{Keywords}

Energy Efficient Development, Mobile Development, smartphone development

\section{INTRODUCTION}

In the modern world, people want 'Always On and Always Connect'. Mobile devices especially Smartphones are very popular in communicative life today. There were 2.7 billion Smartphones that had been subscribed upto November 2014. It is expected to 6.1 billion in 2020 [14]. There are 4.4 billion subscriptions of HSPA/WCDMA and 3.5 billion LTE of subscriptions that in the world at present and is predicted to reach 8.4 billion by 2020 . The research data [14] depict that in 2018 , it is expected that $3 \mathrm{G} / 4 \mathrm{G}$ will represent over $50 \%$ of all active M2M (Mobile-2-Mobile) subscriptions. LTE M2M device penetration is expected to increase from $3 \%$ to $20-30$ percent in the year 2020 .

The research data [14] clearly states that $90 \%$ of the world's population over 6 years old will have a mobile phone by 2020 and it reveals the importance of mobile technology in day to day life. The phrase 'Always On and Always Connect' with mobile batteries is a paradox. Unfortunately, the truth is that it is only the battery backup that decides how long one can use the mobile devices. The reality is, the growth of battery capacity is not equal to the growth of mobile advancement. Hence the responsibility falls on the researchers' to satisfy 6.1 billion users' expectations to be 'Always On and Always Connect'.

\author{
M.Sumathi \\ Dept of Computer Science, \\ Sri Meenakshi Government College for Women, \\ Madurai, India,
}

\section{EVOLUTION OF MOBILE PHONES}

First generation mobile technology established seamless mobile connectivity introducing mobile voice services and the mobile handset supported only monochrome displays. The second generation phones supported digital transmission of voice, data and multimedia applications. These services extended mobile device configurations and display unit and it demanded more operating energy too. In 2.5 generation mobile phones supported GPRS, extended multimedia services and third party software's [1]. These facilities gave rich user experiences and the mobile industries were boomed drastically. The high usage of network activities and multimedia services required massive battery backup. Third generation and LTE(Long Term Evolution) technologies optimized mobile for data enabling mobile broadband services, and is evolving for faster and better connectivity [1] This generation technologies requires high end mobile phones for high speed data transfer, Mobile TV, Video Conferencing, Location-based services and Online games. The ordinary mobile phones do not supports $3 \mathrm{G}$ and $4 \mathrm{G}$ services, it desperately need Smartphone environment.

A Smartphone is a mobile device with more advanced functionalities and features compared to cell phones [2]. A Smartphone's hardware and software specifications are meant to perform functions such as web browsing, capturing highquality images, and playing HD videos. It can install various applications that can perform several advanced functions. Smartphones have become popular because of their many capabilities and is often used for communication and online activities. Advances in technology have led to these phones which are being more compact and cheaper than other mobile devices such as tablets and PDAs.

\section{EMERGING OF SMARTPHONE}

People are in the misbelieve that Smartphones came in to existence only in the last 7 years when Apple introduced Smartphone in mass consumer market, but in reality the Smartphone has been in market since 1993. The difference between today's Smartphone and early Smartphone is that early phones were predominantly meant for corporate users and used as enterprise devices and also those phones were too expensive for the general consumers [5]. Smartphone era is divided into three main phases (see figure 1).

$$
\begin{aligned}
& >\text { Corporate phase (Blackberry) } \\
& >\text { Consumer phase (iPhone) } \\
& >\quad \text { Android era }
\end{aligned}
$$

First phase was purely meant for enterprises. During this phase, all the Smartphones targeted the corporations and its features and functions were as per corporate requirements. This era began with the advent of the very first Smartphone by Simon from IBM in 1993. Blackberry was considered as 
the revolutionary device of this era, that introduced many features including Email, Internet, Fax, Web browsing, Camera. This phase was totally based on Smartphone targeting enterprises [5] [6] [7].

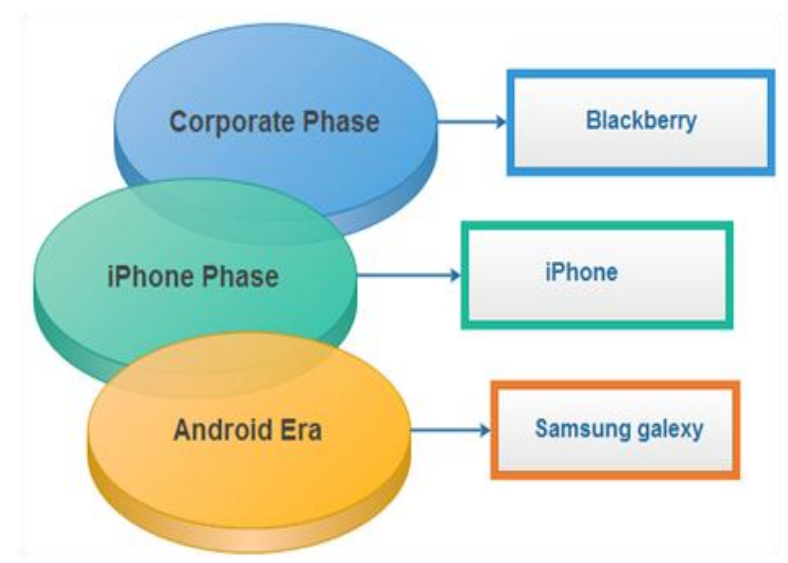

Fig 1: Phases of Smartphone Revolution

The second phase of Smartphone era started with the advent of iPhone, the major breakthrough of Smartphone market in 2007. Apple revealed its first Smartphone in 2007. This was the time when mobile industry introduced the Smartphone in general consumers market for the first time [8]. At end of 2007, Google unveiled its Android Operating System with the intention to approach the consumer Smartphone market. The emphasis during this time period was to introduce features required by the general consumer and at the same time keep the cost at lower level to attract more and more customers. Features like email, social website integration, audio/video, internet access, chatting along with general features of the phone were part of these entire phone [8][9][10][11]. Third phase was mainly closed the gap between enterprise centric and general consumer centric Smartphones provides and many other features.

$>$ Improved display quality and display technology

$>$ Stable mobile operating system,

$>$ High speed data Communication

$>$ Introduce of more powerful batteries

$>$ Enhance the user interface

$>$ Bundle of Mobile Apps

This phase logically started in 2008 with the upgrades in the mobile operating system and within the last five years there have been several upgrades in Apple iOS, Android and Blackberry OS. The most popular mobile operating systems (iOS, Android, Blackberry OS, Windows Mobile) and key Smartphone vendors (Apple, Samsung, HTC, Motorola, Nokia, LG, Sony etc.) are concentrating in bring features both in operating systems and devices which will provide exciting features for enterprise and general consumers. However the role of Android has been tremendous during this time period as it provided a great opportunity to all vendors to build devices using the great open source Android technology [8] [9] [10].

\section{REVOLUTION OF HANDHELD DEVICE BATTERIES}

Power sources are the heart of any electronic devices especially in mobile phones, tablet, laptops, PDA's and other gadgets. The manufacturers and governments invest in research on clean and energy-efficient technologies and longer-lasting batteries to cater for portable electronic devices with power-hungry features. Today, most known and most used batteries are based on

\section{$>$ Lithium-ion (Li-ion) \\ $>$ Nickel-metal-hydride (NiMH), \\ $>$ Lead-acid \\ $>$ Nickel-cadmium $(\mathrm{NiCd})$.}

The Nickel-Cadmium battery ( $\mathrm{NiCd}$ or $\mathrm{NiCad})$ is a type of rechargeable battery using nickel oxide hydroxide and metallic cadmium as electrodes. It has longer cycle life, wider range of operating temperatures and lower price but it consumes enormous time to recharge. While the sale of $\mathrm{NiCd}$ batteries has been legally banned in the European Union due to toxic components [12]. Lead-acid batteries are typically found in applications which require high peak power, for instance, to start a car, or in scenarios, and for uninterruptable power supply where battery weight is a major concern. However, due to their low energy density, lead-acid batteries are not practical viable in the usage of mobile.

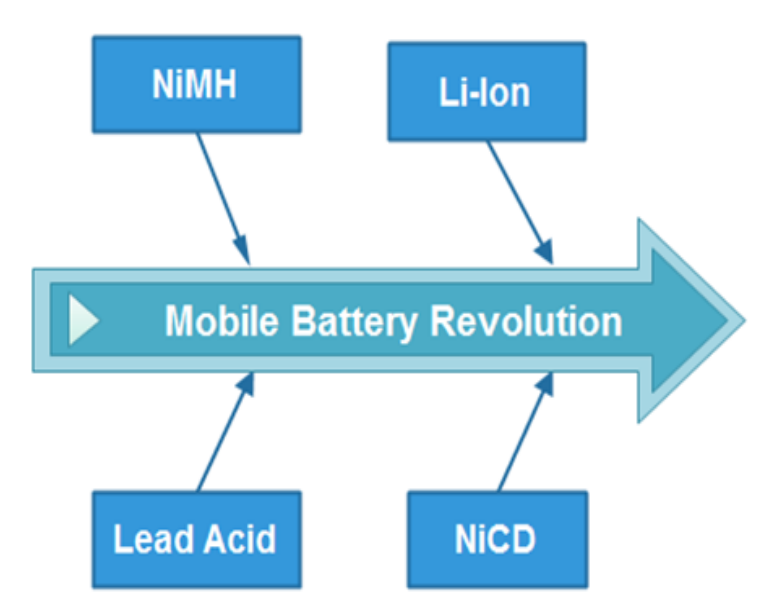

Fig 2. Revolution of Mobile Batteries

For these reasons, Li-ion and NiMH batteries are most commonly used in portable electronic devices, with $\mathrm{Li}$-ion batteries usually offering a higher energy density than NiMH. In addition, Li-ion batteries allow a great number of charge/discharge cycles without memory effect, which ensures a long battery lifetime. It is estimated that Li-ion batteries lose upto 5 percent of charge per month due to selfdischarge processes compared to NiMH batteries which lose upto $30 \%$ per month.

Form and weight are important factors for the choice of batteries in portable devices especially in mobile phones. Liion batteries exist in a wide variety of shapes and sizes while being relatively light weight and apt for mobile phone. Advantages of NiMH over Li-ion batteries include lower cost, high current, and no processor controlled protection circuits are needed. NiMH batteries are often found in digital cameras. 
Table 1. Revolution of Mobile phone Batteries

\begin{tabular}{|c|c|c|c|c|}
\hline Year & $\begin{array}{c}\text { Wireless } \\
\text { Technology }\end{array}$ & Battery Capacity & $\begin{array}{c}\text { Talk time/ } \\
\text { Standby time }\end{array}$ & Model \\
\hline 1983 & Analog voice & Lead acid battery & $1 \mathrm{hr} / 8 \mathrm{hrs}$ & Motorola DynaTAC 8000X \\
\hline 1992 & GSM & $\begin{array}{l}\text { Slim NiCd } \\
380 \mathrm{mAh}\end{array}$ & $45 \mathrm{~min} / 11 \mathrm{hr}$. & Nokia 101 (First GSM Phone) \\
\hline 1996 & GSM & NiMH 500 mAh. & $2.8 \mathrm{hrs} / 75 \mathrm{hrs}$ & $\begin{array}{c}\text { Motorola StarTAC ( First Flip } \\
\text { phone) }\end{array}$ \\
\hline 1998 & GSM & Li-Po 600 mAh. & $2 \mathrm{hrs}-3 \mathrm{hrs} 20 \mathrm{~min} / 40-180 \mathrm{hrs}$ & Nokia 5110 \\
\hline 1999 & GSM & NiMH 1250 mAh & $4 \mathrm{~h} 30 \mathrm{~min} / 55-260 \mathrm{~h}$ & Nokia 3210 \\
\hline 2000 & GSM & 1000 mAh Li-Ion & $2: 30 \mathrm{hrs}$ to $4: 30 \mathrm{~h} / 55 \mathrm{~h}$ to $245 \mathrm{~h}$ & Nokia 3310 \\
\hline 2003 & GSM & Li-Ion 850 mAh battery & $2-4.5$ hours / $100-400$ hours & Nokia 1100 \\
\hline 2005 & GSM/UMTS & Li-Po $1500 \mathrm{mAh}$ & Up to $6 \mathrm{hrs} / \mathrm{Up}$ to $216 \mathrm{hrs}$ & Nokia N92 (Mobile TV) \\
\hline 2006 & $\begin{array}{c}\text { GSM } \\
\text { /WCDMA }\end{array}$ & Li-Ion $970 \mathrm{mAh}$ & Up to $3.5 \mathrm{hrs} / \mathrm{Up}$ to 11 days & Nokia N70 \\
\hline 2006 & GSM/HSPA & Li-Ion 1500 mAh & $\begin{array}{c}15 \mathrm{~h}(2 \mathrm{G}) \& 7 \mathrm{~h}(3 \mathrm{G}) / 600 \mathrm{~h} \\
(2 \mathrm{G}) \& 550 \mathrm{~h}(3 \mathrm{G})\end{array}$ & $\begin{array}{l}\text { Samsung S8500 (First } \\
\text { AMOLED) Nokia 6215i (First } \\
\text { OLED) }\end{array}$ \\
\hline 2008 & $\begin{array}{l}\text { GSM/EDGE } \\
\text { /HSPA }\end{array}$ & $\begin{array}{l}1220 \text { mAh Non- } \\
\text { removable Li-Ion battery }\end{array}$ & $10 \mathrm{~h} / 300 \mathrm{~h}$ & Apple i-Phone 3G \\
\hline 2008 & $\begin{array}{l}\text { GSM/UMTS } \\
\text { /HSPDA }\end{array}$ & Li-Ion 1000 mAh & $3 \mathrm{hrs} / 250 \mathrm{hrs}$ & Samsung SGH-F480 \\
\hline 2009 & $\begin{array}{l}\text { GSM/UMTS/ } \\
\text { HSPA/UMTS }\end{array}$ & Li-Ion $1340 \mathrm{mAh}$, & $8 \mathrm{hrs} / 600 \mathrm{hrs}$ & HTC Magic, \\
\hline 2010 & GSM/HSPA & Li-Ion $1,420 \mathrm{mAh}$ & $\begin{array}{c}12 \mathrm{~h}(2 \mathrm{G}) \& 5 \mathrm{~h} 50 \mathrm{~min}(3 \mathrm{G}) / \\
390 \mathrm{~h}(2 \mathrm{G}) \& 400 \mathrm{~h}(3 \mathrm{G})\end{array}$ & iPhone 4 \\
\hline 2011 & GSM/HSPA & Li-Ion $1650 \mathrm{mAh}$ & $\begin{array}{l}18 \mathrm{~h} 20 \min (2 \mathrm{G}) \& 8 \mathrm{~h} 40 \mathrm{~min} \\
(3 \mathrm{G}) / 710 \mathrm{~h}(2 \mathrm{G}) \& 610 \mathrm{~h}(3 \mathrm{G})\end{array}$ & Samsung I9100 Galaxy S II \\
\hline 2012 & GSM/HSPA & Li-Ion $2100 \mathrm{mAh}$ & $\begin{array}{l}21 \text { h } 40 \min (2 \mathrm{G}) \& 11 \text { h } 40 \text { min } \\
(3 \mathrm{G}) / 590 \mathrm{~h}(2 \mathrm{G}) / 790 \mathrm{~h}(3 \mathrm{G})\end{array}$ & Samsung Galaxy S III \\
\hline 2013 & $\begin{array}{l}\text { GSM/HSPA } \\
\text { /LTE }\end{array}$ & Li-Ion $2800 \mathrm{mAh}$ & $21 \mathrm{~h}(3 \mathrm{G}) / 390 \mathrm{~h}(3 \mathrm{G})$ & Samsung Galaxy S4 \\
\hline 2014 & $\begin{array}{l}\text { GSM/HSPA } \\
\text { /LTE }\end{array}$ & Li-Ion $2600 \mathrm{mAh}$ & $17 \mathrm{~h}(3 \mathrm{G}) / 370 \mathrm{~h}(3 \mathrm{G})$ & Samsung Galaxy S5 \\
\hline 2015 & GSM/HSPA & Li-Po $4000 \mathrm{mAh}$, & $43 \mathrm{~h}(2 \mathrm{G}) \& 25 \mathrm{~h}(3 \mathrm{G}) / 840 \mathrm{~h}$ & Lenovo P780 \\
\hline
\end{tabular}




\section{NECESSITY FOR ENERGY EFFICIENT SMARTPHONE DEVELOPMENT}

High performance usually requires power sacrifices. The objective is to find a perfect balance between these two within a particular design. Optimum performance with low power is the ultimate target here. There are numbers of designs and process strategies for achieving economical performance at system level, Network and GUI, with long battery life (see figure 3 ).

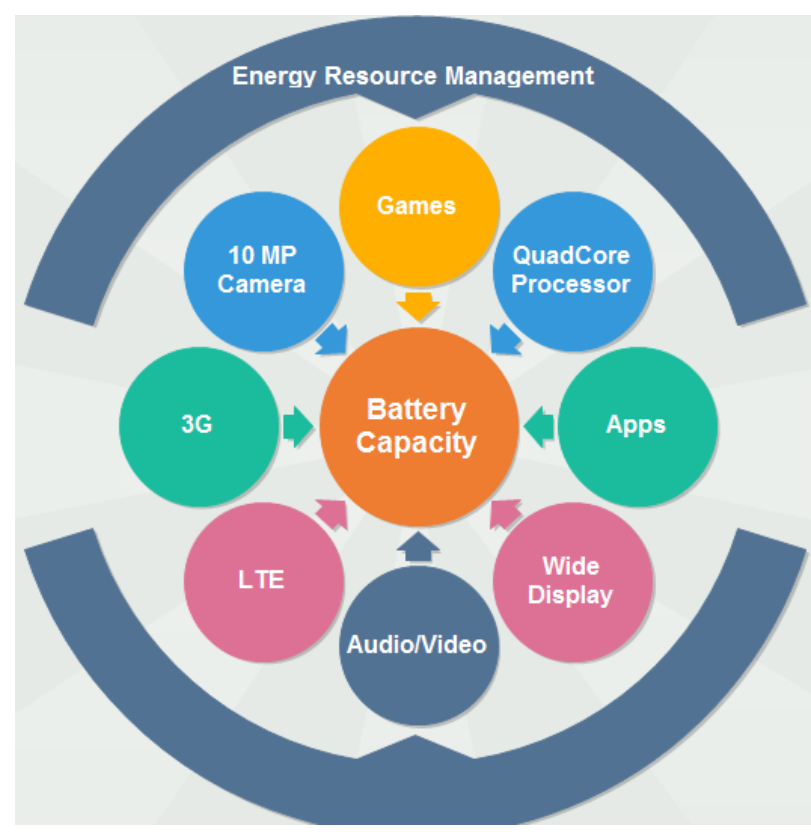

Fig 3. Energy Resources Management

Shannon's law predicts that the transmission performance improves by two times in 8.5 months. Given Moore's law, semiconductor manufacturers take 18 months to double the number of transistors and therefore double the microprocessor performance. In addition, battery makers take 5 to 10 years to achieve comparable increase in power density (See Table 1). These gaps are the major hurdles for successful commercialization of mobile devices.

The portable devices that free people to go anywhere anytime also keeps them tethered by electrical power cords, plugs, and sockets. Sophisticated devices with multimode radios, color displays, 3D audio, video, and gaming features demand more from batteries backup. Interestingly this has leaded the users of portable devices to become "socket seekers." Each year batteries become more powerful and circuitry improvements make devices more efficient but unfortunately this does not give feed to devices hungry.

The Table 1 shows the basic model of (first generation) mobile phone that required the range of $300 \mathrm{mAh}$ to $600 \mathrm{mAh}$ battery capacity with $45 \mathrm{~min}$ to $3 \mathrm{hrs}$ of talk time. These generation phones have only basic display (Monochrome) and basic GSM communications so that it required minimum operating power. The second generation phones demanded the power range from $800 \mathrm{mAh}$ to $1600 \mathrm{mAh}$ because of enhanced display and networking (2.1 inch TFT LCD display, Dual ARM 9 CPU, Symbian OS, 2 MP Camera and Wi-FI, GPRS) so that it offered an average of $4 \mathrm{hrs}$ to $10 \mathrm{hrs}$ of talk time and operating times. Third generation phones provided advanced services (1 GHz Cortex-A8 CPU, Bada OS, Android, iOS, OLED, Super AMOLED capacitive touch screen with $16 \mathrm{M}$ colors 3.3 inches, $5 \mathrm{MP}$ camera with $2592 \mathrm{x}$ 1944 pixels). These services required minimum of $1500 \mathrm{mAh}$ to $2500 \mathrm{mAh}$ for comfortable usage. If the users want to use the feature as per the specifications, it will demand minimum of $2500 \mathrm{mAh}$ to $3500 \mathrm{mAh}$ battery power for a day. The table 1 shows that from the year 1992 to 2013 the battery capacity increased only to $2420 \mathrm{mAh}$ in but $21^{\text {st }}$ century, people use the mobile phone $24 \times 7$, parallelly the phone features and Apps grow each \& every minute to meet their expectations. The growth rate of mobile phone specification is $25 \%$ and the growth rate of portable rechargeable (Li-Ion) battery is $10 \%$ [13]

However, batteries cannot cope-up with the rising expectations for longer life and its leads to the research on energy efficient software development. Whatever the physical component technologies are developing that will controlled by software's. Obviously the software is the soul of every handheld devices and it plays a vital role in regulating the power consumption. The typical energy efficient software minimizes power consumption and extends the battery life.

\section{CONCLUSION}

This paper discusses and reveals the evolution of mobile technology from first generation to present generation. It depicts why modern people want Smartphones. This study talks about the battery capacity and operating methods of first generation mobile phone and further it moves towards the present status.

This paper emphasizes the reason behind the need of energy efficient mobile development and also points out the lacking of present generation mobile phone batteries with statistical data. It clearly picture out the gap between the growth rate of mobile technology(i.e 25\%) and battery capacity(i.e 10\%). This gap will be reduced by energy efficient researches. In future the author will continue the research of reducing the energy consumption by display unit, GSM and Wifi.

\section{REFERENCES}

[1] C. S. Patil, R.R.Karhe , M. A. Aher 2012. Development of Mobile Technology: A Survey. International Journal of Advanced Research in Electrical, Electronics and Instrumentation Engineering Vol. 1, Issue 5.

[2] Masoud Nosrati, Ronak Karimi, Hojat Allah Hasanvand. 2012. Mobile Computing: Principles, Devices and Operating Systems. World Applied Programming, Vol (2), Issue (7), pp. 399-408.

[5] Brad Reed, 2010. A brief history of Smartphone's. http://www.networkworld.com/slideshows/2010/061510smartphone-history.html\#slide1

[6] James Niccolai, Nancy Gohring, 2010. A Brief History of Palm. http://www.pcworld.com/article/195199/ article.html.

[7] Wikipedia, 2012. Blackberry, http://en.wikipedia.org/ wiki/BlackBerry.

[8] Hamza Querashi, 2012. Apple: from iPhone 1 to iPhone 5 - Evolution, Features and Future Review. http://www.thenewstribe.com/2012/07/16/apple-fromiphone-1-to-iphone-5-evolution-features-and-futurereview/ 
[9] Sam Costello, 2012. First-Generation iPhone Review, http://ipod.about.com/od/iphoneproductreviews/fr/iphone _review.htm

[10] Chris Ziegler, 2011. Android: A visual history. http://www.theverge.com/2011/12/7/2585779/androidhistory

[11] Mark Prigg, 2012 http://www.dailymail.co.uk/ sciencetech/article-2225149/Windows-8-phone-softwarelaunch-Microsoft-hopes-Jessica-Alba-help-AppleGoogle.html.
[12] European Union: 2003. Directive on the restriction of the use of certain hazardous substances in electrical and electronic equipment" 2002/95/EC

[13] M. Yoshio, R. J. Brodd, and A. Kozawa, eds., 2009. Lithium-Ion Batteries: Science and Technologies, Springer.

[14] Technical report 2014. Ericsson Mobility Report, www.ericsson.com. 